
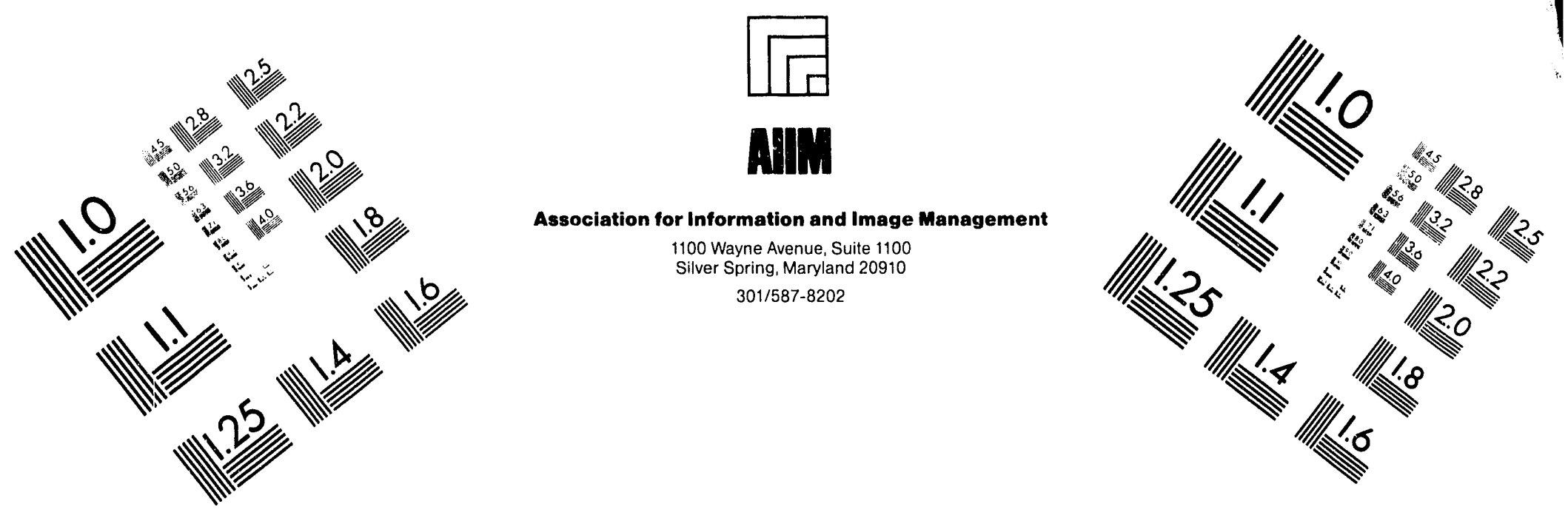

\title{
Centimeter
}

$\begin{array}{llllllllllllllll}1 & 2 & 3 & 4 & 5 & 6 & 7 & 8 & 9 & 10 & 11 & 12 & 13 & 14 & 15 & 15 m\end{array}$

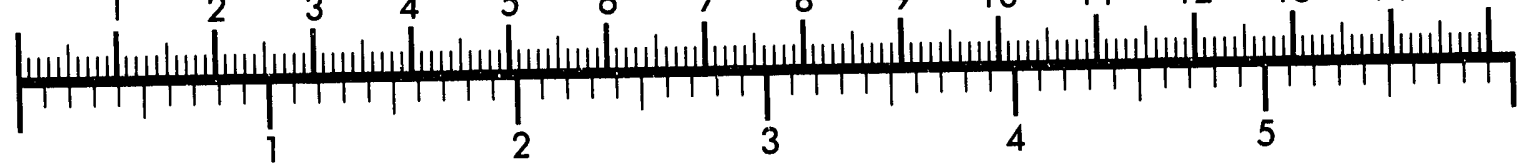

Inches
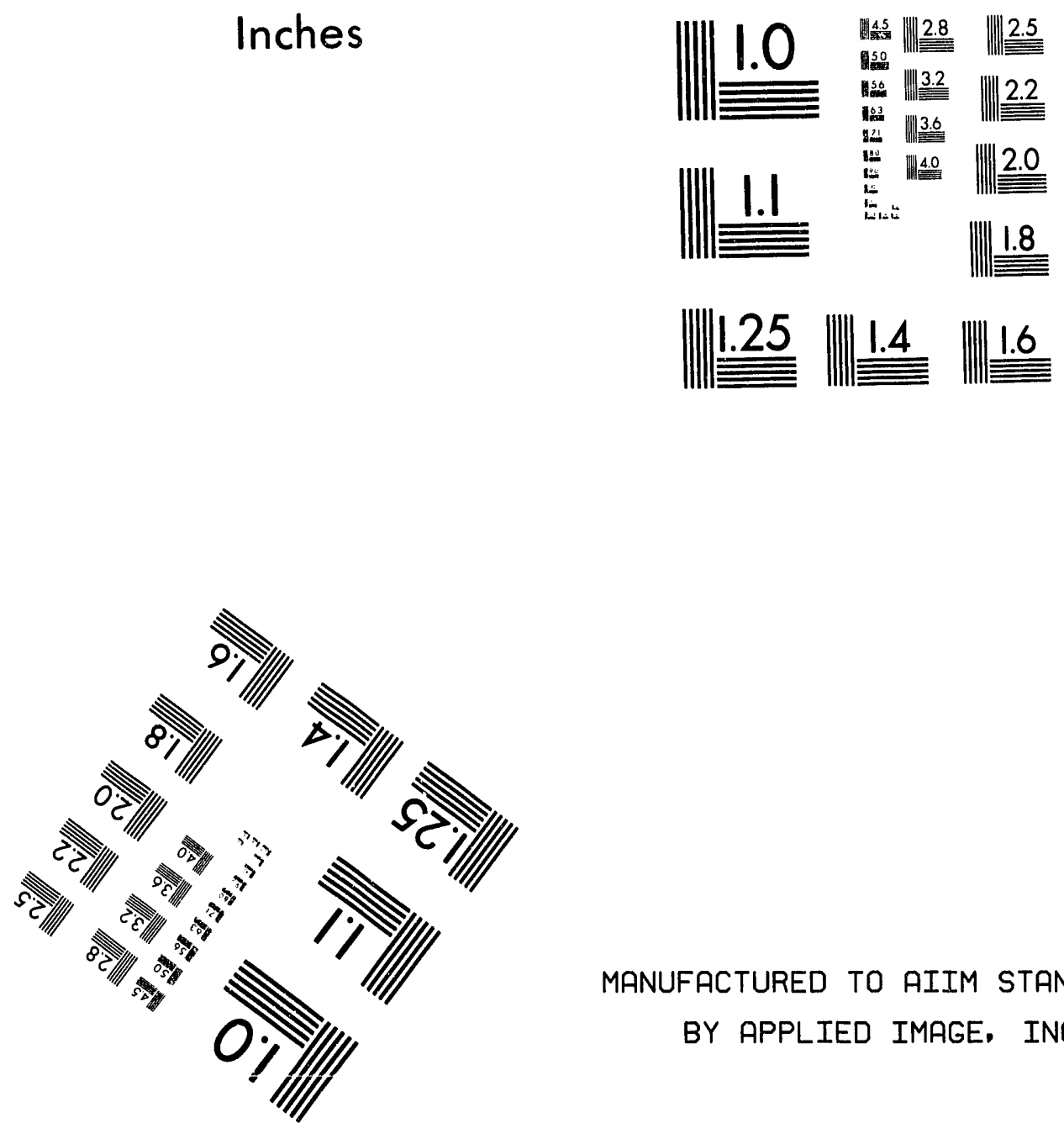

MANUFACTURED TO AIIM STANDARDS

BY APPLIED IMAGE, INC.

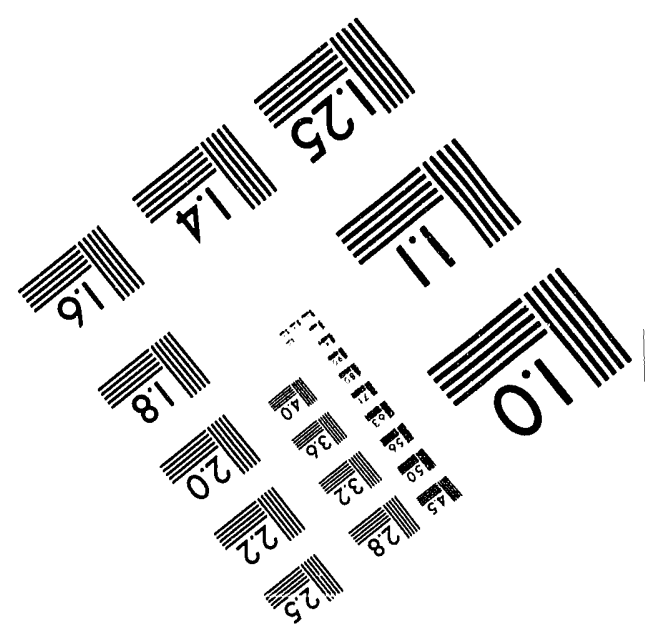



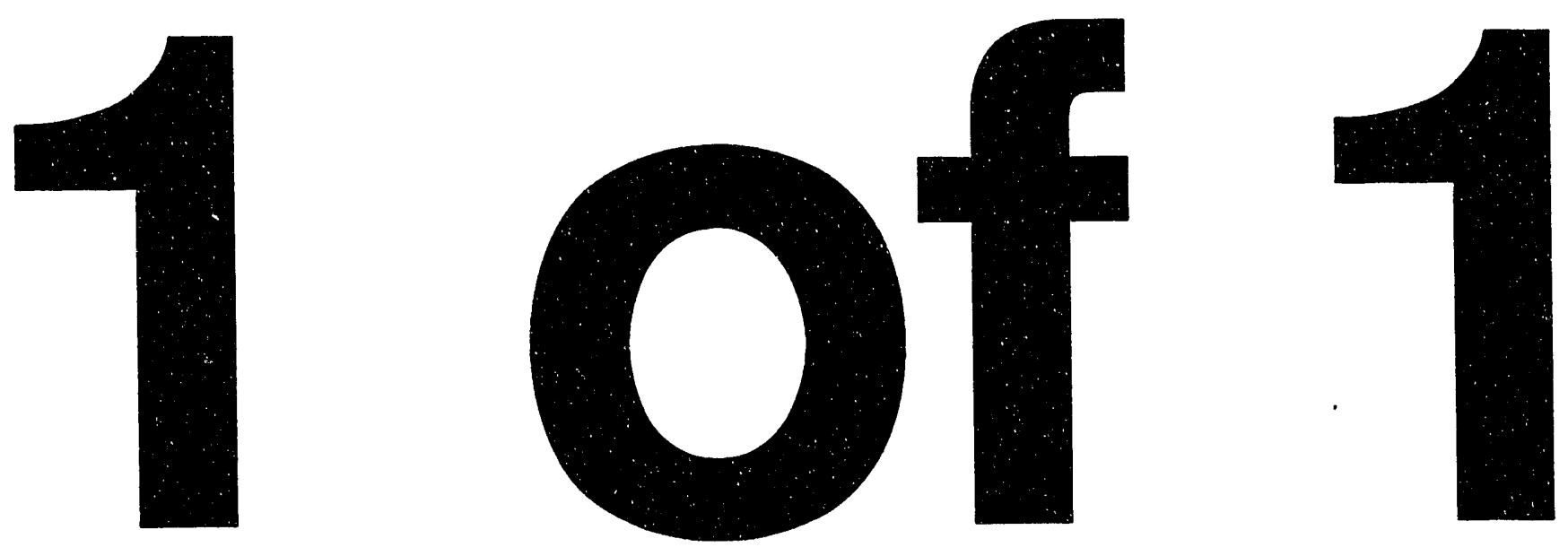
Instrumentation and Controls Division

\title{
AN OPTICAL TECHNIQUE FOR CHARACTERIZING THE LIQUID PHASE OF STEAM AT THE EXHAUST OF AN LP TURBINE
}

\author{
Stephen W. Kercel \\ Dr. Marc L. Simpson \\ Oak Ridge National Laboratory \\ P. O. Box 2008 \\ Oak Ridge, TN 37831 \\ Dr. Mary Azar \\ Tennessee Technological University \\ Cookeville, TN 38505 \\ Mel Young \\ Alabama Power \\ Parrish, AL 35580 \\ ANS Publications Department \\ Nuclear Plant Instrumentation Topical \\ 555 N. Kensington Avenue \\ La Grange Park, IL 60525

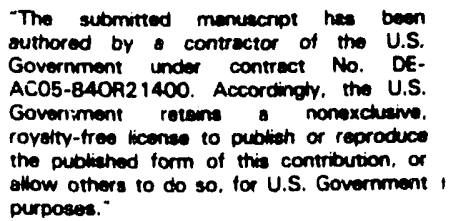

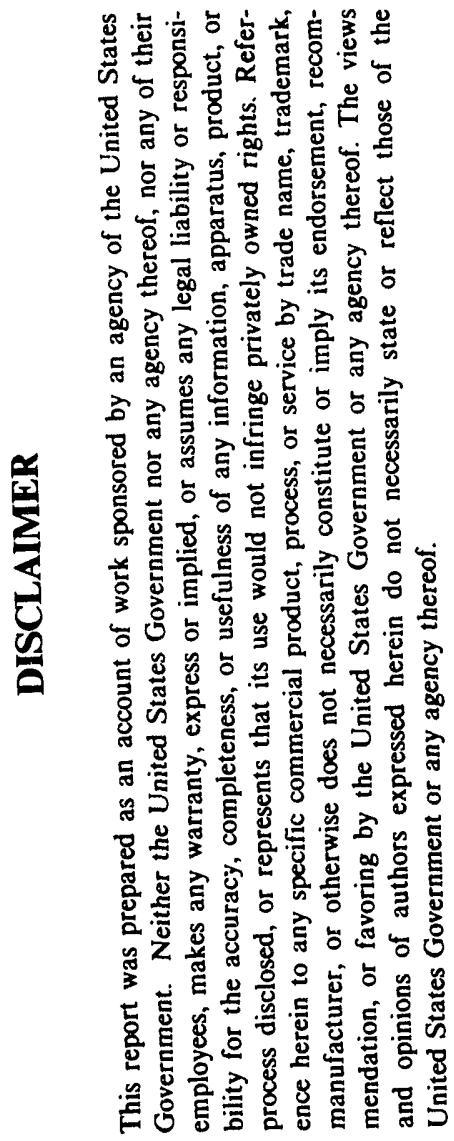

*Research sponsored by the U. S. Department of Energy and performed at Oak Ridge National Laboratory, managed by Martin Marietta Energy Systems, Inc. for the U. S. Department of Energy under Contract No. DEAC05-840R21400. 


\section{AN OPTICAL TECHNIQUE FOR CHARACTERIZING THE LIQUID PHASE OF STEAM AT THE EXHAUST OF AN LP TURBINE*}

\author{
Stephen W. Kercel \\ Dr. Marc L. Simpson \\ Oak Ridge National Laboratory \\ PO Bnx 2008 \\ Oak Ridge IN 37831 \\ (615) $574-5278$
}

\author{
Dr. Mary Azar \\ Tennessee Technological University \\ Cookeville, TN 38505 \\ (615) 574-5278
}

Mel Young

Alabama Power

Parrish AL 35580

(205) $250-1157$

\section{ABSTRACT}

This paper describes the measurement of the size and velocity of particles based on the observation and analysis of visibility patterns created by backscaltered circularly polarized light. The size of latex particles in a dry nitrogen stream was measured in the laboratory. Visibility patterns of water droplets were observed in the low pressure lurbine of Unit 6 of Alabama Power's Gorgas Steam Plant.

\section{INTRODUCTION, AND BACKGROUND}

Optical observation of velocity and size of water droplets in powerplant steam has several applications. These include the determination of steam wetness fraction, mass flow rate, and predicting erosion of turbine blades and pipe elbows. The major advantages of optical techniques are that they do not interfere with the flow or perturb the observation!

An optical probe volume is formed by splitting a laser beam and passing the resulting beams through a converging lens. Where the two beams intersecl, they form an interference fringe pattern (Figure 1). A small particle passing through the probe volume scatters light in proportion to the intensity of the incident light ${ }^{2}$.

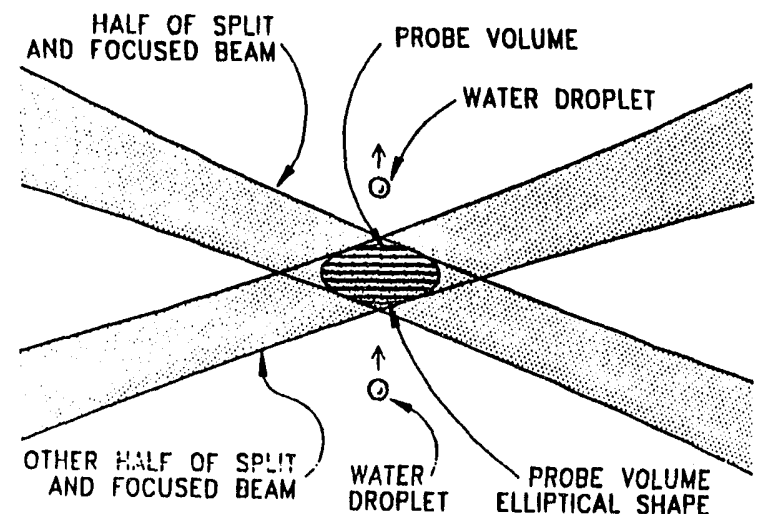

Fig. 1 Formation of Probe Volume by Focused Coherent Beams

Several properties of a single particle can be observed from the scattered light. As the particle passes through the fringes in the

* Research sponsored by the U. S. Departinent of Energy and performed at Oak Ridge National Laburatory. managed by Martin Marietta Energy Systems, Inc., for the U. S. Department of Energy under contract DE-ACOS-84OR21400 probe volume, the intensity of the scattered light varies with time, and is observed by an optical detector as a visibility pattern whose properties depend on the size and velocity of the particle (Figure 2). Visibility $V$, is a metric of the visibility pattern. It is given by

$$
V=\frac{I_{\max }-I_{\min }}{I_{\max }+I_{\min }}
$$

where $I_{\max }$ is the peak intensity and $I_{\min }$ is the intensity of the first null after the peak.

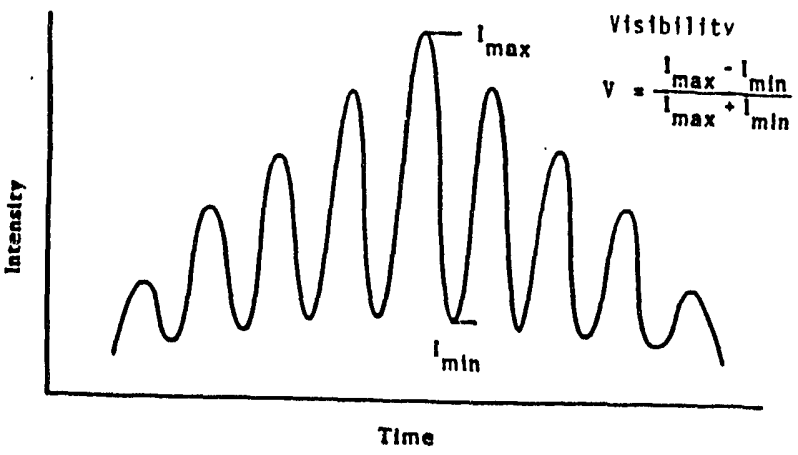

Fig. 2 A typical visibility pattern produced by a particle passing through the center of the probe volume

Given the visibility pattern, it is a straight-forward matter to deduce the size and velocity of the particle. For forward scattering an approximate relationship between particle size and visibility was developed by Farmer,

$$
V=\frac{2 J_{1}\left(\frac{\pi d}{\delta}\right)}{\left(\frac{\pi d}{\delta}\right)}
$$

In Farmer's Law, $d$ is particle diameter, $d$ is fringe period, and $J_{1}$ is a first order Bessel function of the first kind ${ }^{3}$.

It is convenient to observe the backscatter. Only one viewport is needed, and the sane optics are used to form the probe volume and collect the scattered light, simplifying alignment. While Farmer's Law works for forward scatter, it breaks down in backscatter. The law is based on the assumption that the forward Jobe of the Mie scaltering pallern dominates the side lobes, and that the side lobes can be ignored. Figure 3a shows the back and side lobes in relation to the front lobe for the Mie scattering pattern of a typical particle 4 . 


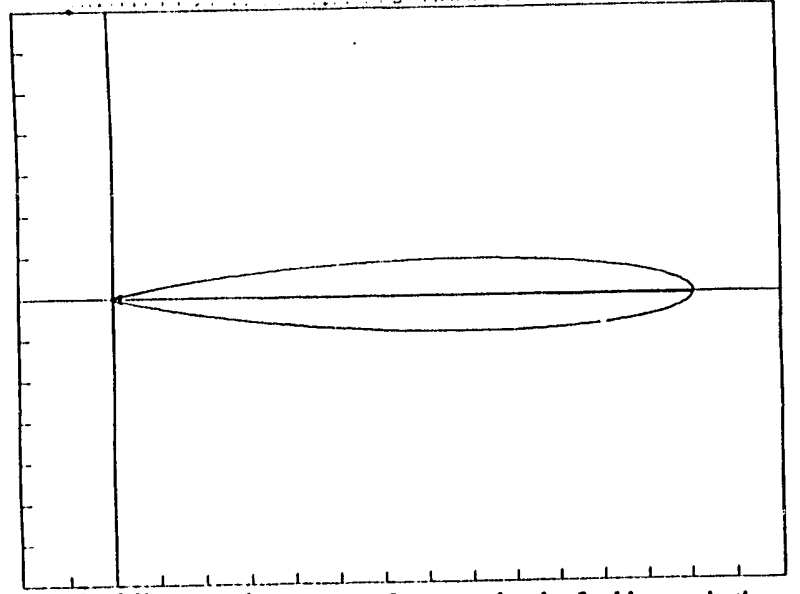

Fig. 3a Mie scaltering pattem of a water droplet for blue excitation

As seen in Figure 3b, the back lobe in Mie scattering is on the same order as the sidelobes. Thus, in observing backscatter, the side lobes must be considered. The strength of the side lobes is extremely sensitive to the conductivity (or imaginary component of refractive index) of the particle. Negus and Drain found that this sensitivity to conductivity is much less pronounced for circularly polarized light, and that a relationship between particle size and the visibility of backscattered circularly polarized light could be derived from exact Mie scaltering 5 , An example is shown in Figure 4.

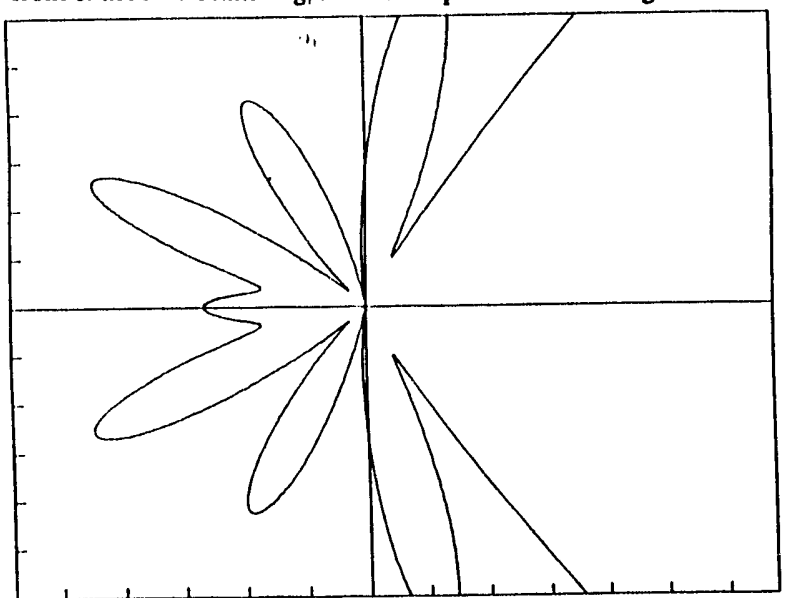

Fig. 3b Back and side lobes of the Mie Scattering pattern of a water droplet for blue excitation

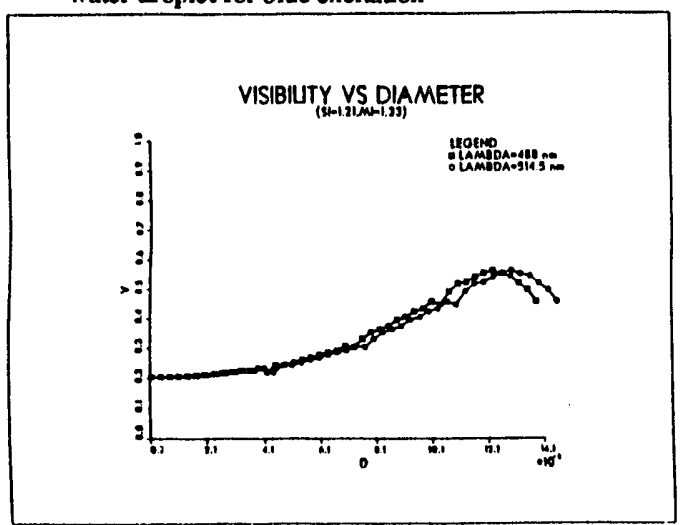

Fig. 4 Visibility as a function of particle diameter computed from Mie backscatter

\section{LABORATORY OBSERVATION OF LATEX PARTICLES}

Experimental observation of backscattered visibilty patterns of particles of known size, using circularly polarized excitation, indicates that the relationship between visibility and size derived from exact Mie scattering law does accurately describe the relationship between visibility and size to within reasonable experimental error, and is monotonic over a useful range of particle sizes.

The experimental setup is shown in Figures 5 and 6 . The linearly polarized $488 / 514 \mathrm{~nm}$ (blue-green) beam from an Argon ion laser was split into two components of equal intensity. The split beams were circularly polarized by passing through a quarter wave plate. The probe volume was formed by passing the two circularly polarized beams through a $310-\mathrm{mm}$ converging lens. The view port was a quartz optical flat.

Latex spheres suspended in water were fed into the stream by a nebulizer driven by pressurized dry nitrogen. Dry nitrogen fed directly into the stream evaporated the water as the stream passed through the drying section. This resulted in a sparse stream of latex spheres passing through a glass tee. The stream was sparse enough that one sphere at a time passes through the probe volume.

As a sphere passed through the probe volume it scattered the light. The scattered light consisted of a reverse circularly polarized component and several elliptically polarized components. The lens intercented part of the scattered light. The quarter wove plate converted the circular polarization to linear polarization and the elliptically polarized components to other elliptical polarizations. The collector reflected the light to a color separator, blue in one direction, green in the other. The linear polarizer filtered out the elliptically polarized components. The resulting linearly polarized blue and green beams were detected by photomultiplier tubes. The resulting electric currents were amplified, and displayed versus time on an oscilloscope. A typical scope trace is shown in Figure 7.

Results for several sizes of latex particles are shown in Figure $8^{6}$. The solid line is the relationship hetween visibility and sphere diameter derived from exact Mie scattering. Many observations were made for spheres diameters of $0.9,1.04,2.02$, and 2.9 microns. The bars indicate the range of visibilities observed for each sphere diameter.

The 0.9 and $\mathbf{2 . 9}$ micron particles resulted in lower visibility than was expected. This is attributed to uncertainty in the measurement of the angle between the split excitation beams. The relationship between visibility and diameter is extremely sensitive to beam angle.

\section{FIELD OBSERVATION OF WATER DROPLETS IN STEAM}

Ohservations were conducted on the low pressure (LP) turbine of Unit 6 at Nlabama Power's Gorgas Steam Plant. The experimental setup is shown in Figures 9, 10, and 11. The optical system was the same as was used for the latex observations, except that a 1200-mm front lens was used (the longest focal length available as a shelf item). The view port consisted of a quartz optical nat mounted in a flange in a removable hatch cover in the turbine hood.

As shown in Figure 10, the focal length tumed out to be too short to reach into the main stream flow at the discharge of the last stage turbine blades. Consequently, while visibility patterns were observed, as in Figure 12, they appear to represent large slow moving water particles being thrown off the turbine blades rather than sinall fast moving particles in the main flow stream. The observed patterns were very unrepresentative of the visibility 
patterns expected from water droplets in main stream flow. Consequently, a detailed analysis of the observed patterns was considered meaningless and was not performed. Nevertheless, the experiment showed that it is possible to observe droplets in a "real world" situation.

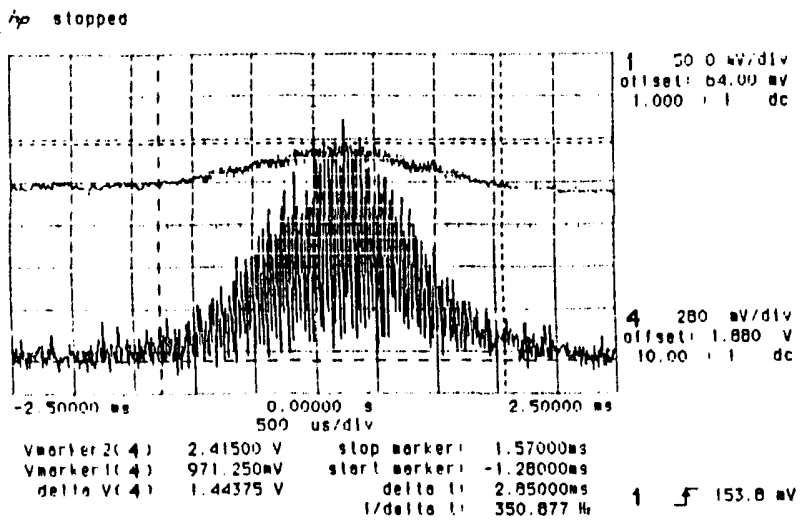

Fig. 7 Typical visibility paltem of a $2.9 \mathrm{~m}$ latex particle with circularly polarized excitation.Layout)

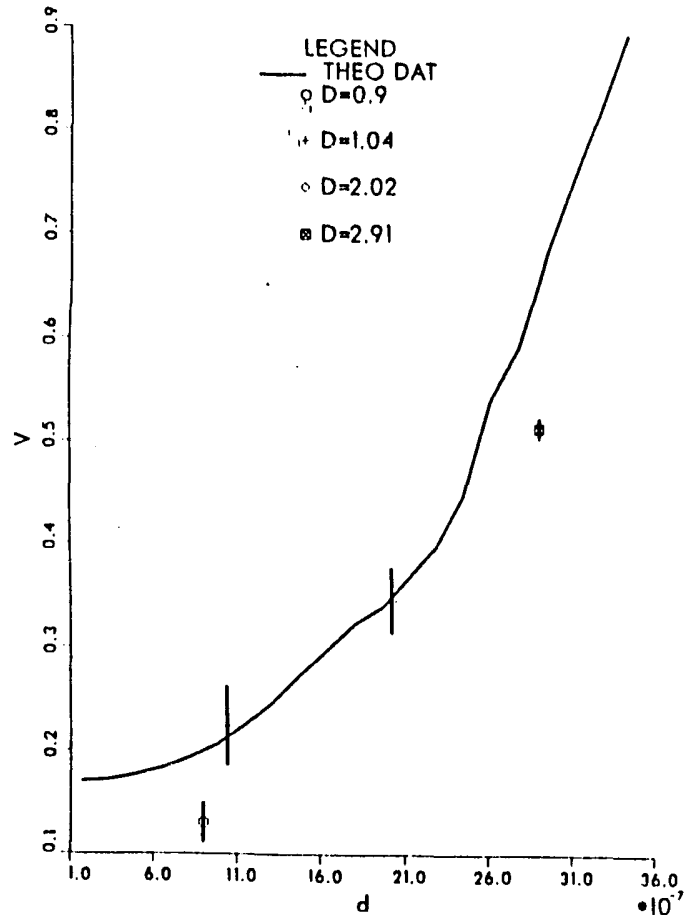

Fig. 8 Observed versus predicted visibilities of particles of a given size.

\section{CONCLUSIONS AND FURTHER RESEARCH}

These experiments lead to two major conclusions. First, by using circularly polarized light and a visibility-versus-size relationship derived from exact Mie scaltering, it is possible to observe particle size within reasonable experimental error. Second, it is possible to observe backscattered visibility patterns of water droplets in a "real world" stearn turbine. These findings constitute a prof of principle. It is practical to measure the size and velocity of water droplets in a commercial steam turbine through a single vicw port without perturbing the flow by observing the visibility pattern of backscattered circularly polarized light.
The next step in the research will be to modify the optical apparatus so that the system can "see" particles in the main flow stream flow at the discharge of the last stage turbine blades. This will require a custom ground $1500-\mathrm{mm}$ lens in place of the existing 1200-min lens, and will create the problem of an inconveniently long probe volume. To overcome this, the receiving optics must be modified to observe a short, but selectable, field of view in the probe volume. These two changes should make it possible to observe single particle events in the main flow siream of the turbine.

A further step will he to consider multiple particle events ${ }^{7}$ Multiple particles simultaneously passing through the probe volume create a complex pattern of backscattered intensity as a function of time. From this, it is expected to be possible to deduce the distribution of sizes and velocities of particles passing through the probe volume. From these distributions, it should be possible in calculate the wetness fraction of the steam exiting the last stage of the turbine, mass now through the turbine, and LP turbine efficiency.

\section{REFERENCES}

1. A. EDERHIOF, and G. DIBELIUS, "Deternination of Droplet Sizes and Wetness Fraction of Two-Phase Flows Using a Light Scattering Technique (high pressure live steam of nuclear power plants, low pressure steam turbines; cooling tower plumes)," 6th Thennodynamics and Fluid Mechanics Convention, Durban, NC, 1 Mech E Conference Publication 1976-6, 6-8 April 1976.

2. M.L. SIMPSON et al, "Single Port, Two Color Particle Sensing System for Characterizing Wet Stcam," Sensors Expo Proceedings 1990. Helmers Publishing, Peterborough NII, (1990).

3. W.M. FARMER, "Measurement of Particle Size, Number Density, and Velocity Using a Laser Interferometer," Applied Optics, Vol 11, p. 2603, (1972).

4. M. BORN and E. WOIF, Principles of Qolics, Pergamon Press, New York, pp. 633-664, (1965).

5. NEGUS and DRAIN, LoumaL of Applied_Physics D, p.375, (1982).

6. AZAR and VENIRICE, "Visibility Measurements of Lalex Particles Using L,DA Technique in the Backscalter Direction," Report No. A-V-91-1, submitted to ORNL by 'ITU Center for Electric Power, Cookeville TN, (1991).

7. W.D. BACIIAI,O and M.J. HOUSER, "Phase/Doppler Spray Analyzer for Simultaneous Measurements of Drop Size and Velocity Distributions," Oplical Engineering, Vol. 23, No. 5 , (1984) 


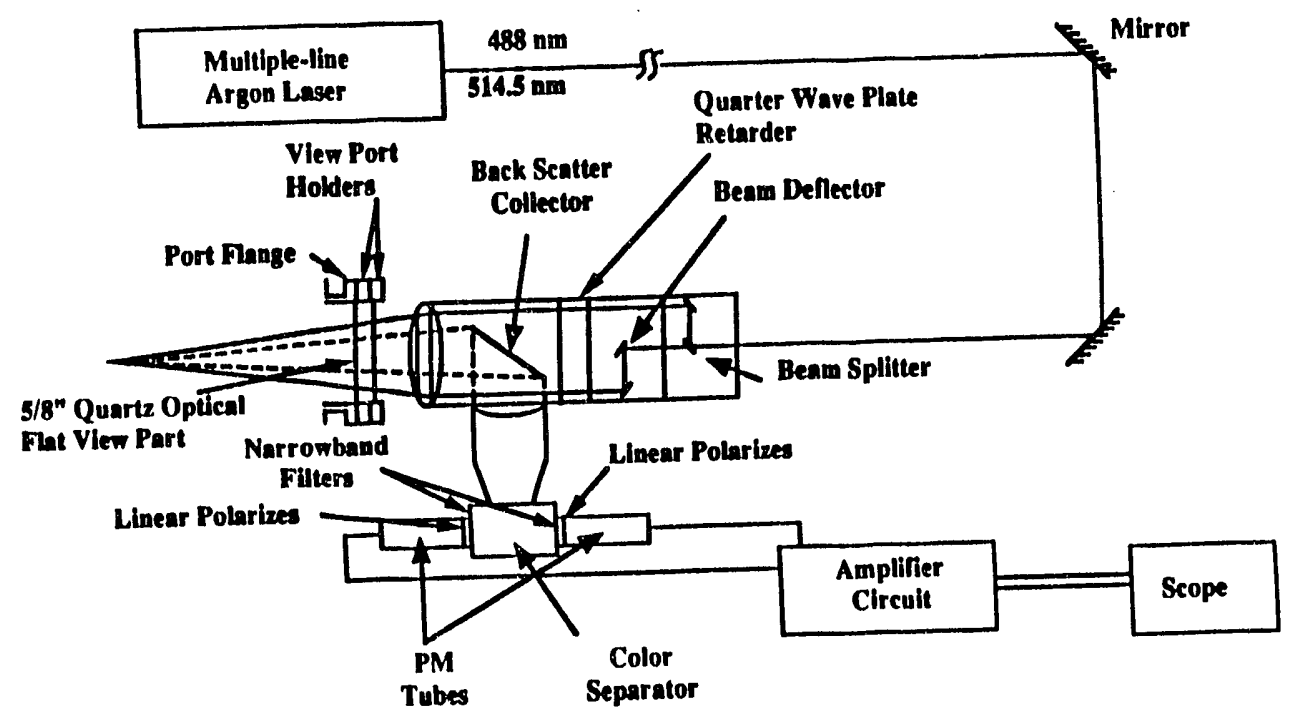

Fig. 9 Field setup for observing visibility patterns of watcr droplets in a turbine.

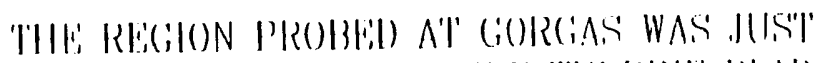
OU'ISIDE' 'I'IE' LOW PRLSSSURE' 'IUURBINL', BLADL'

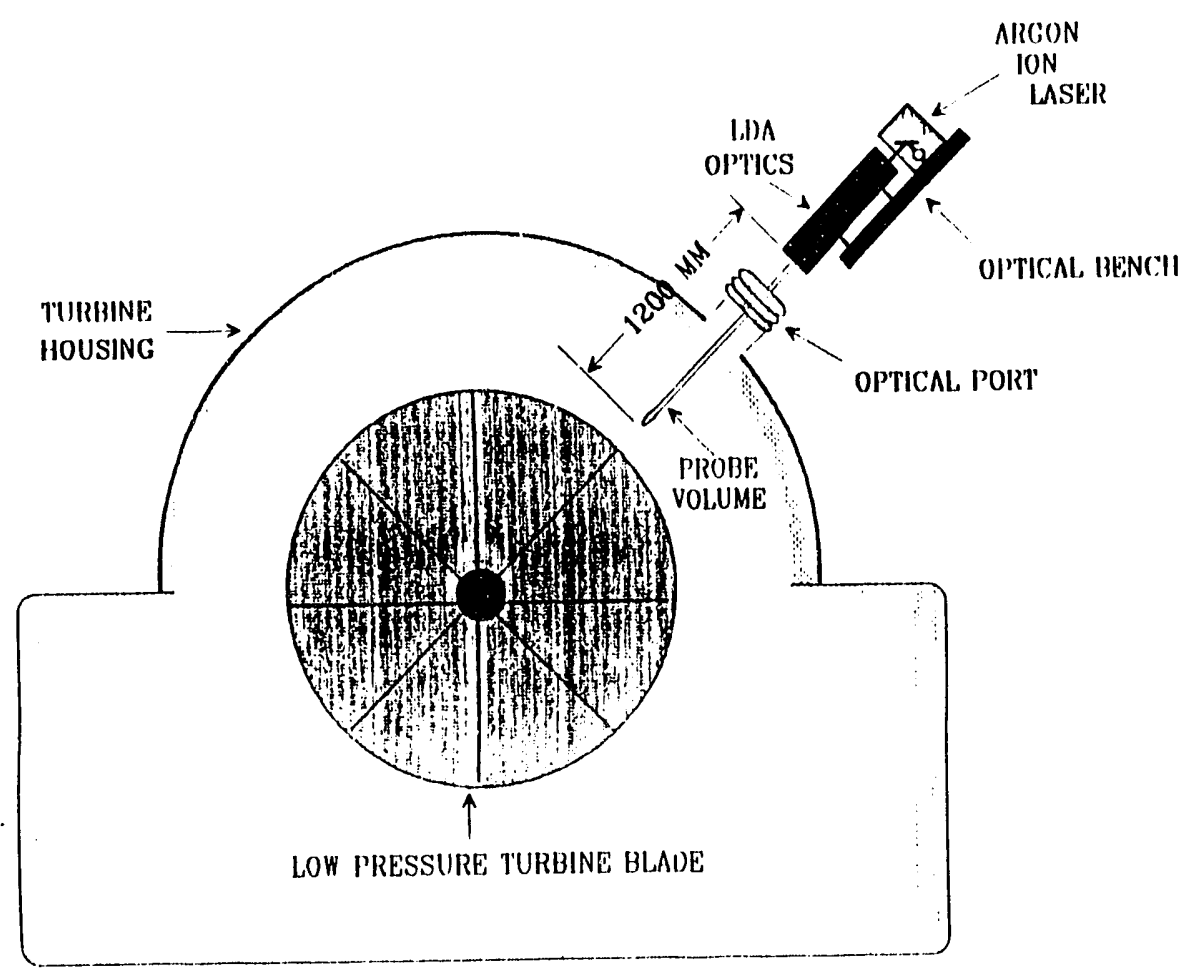

Fig. 10 Region probed by the setup. 


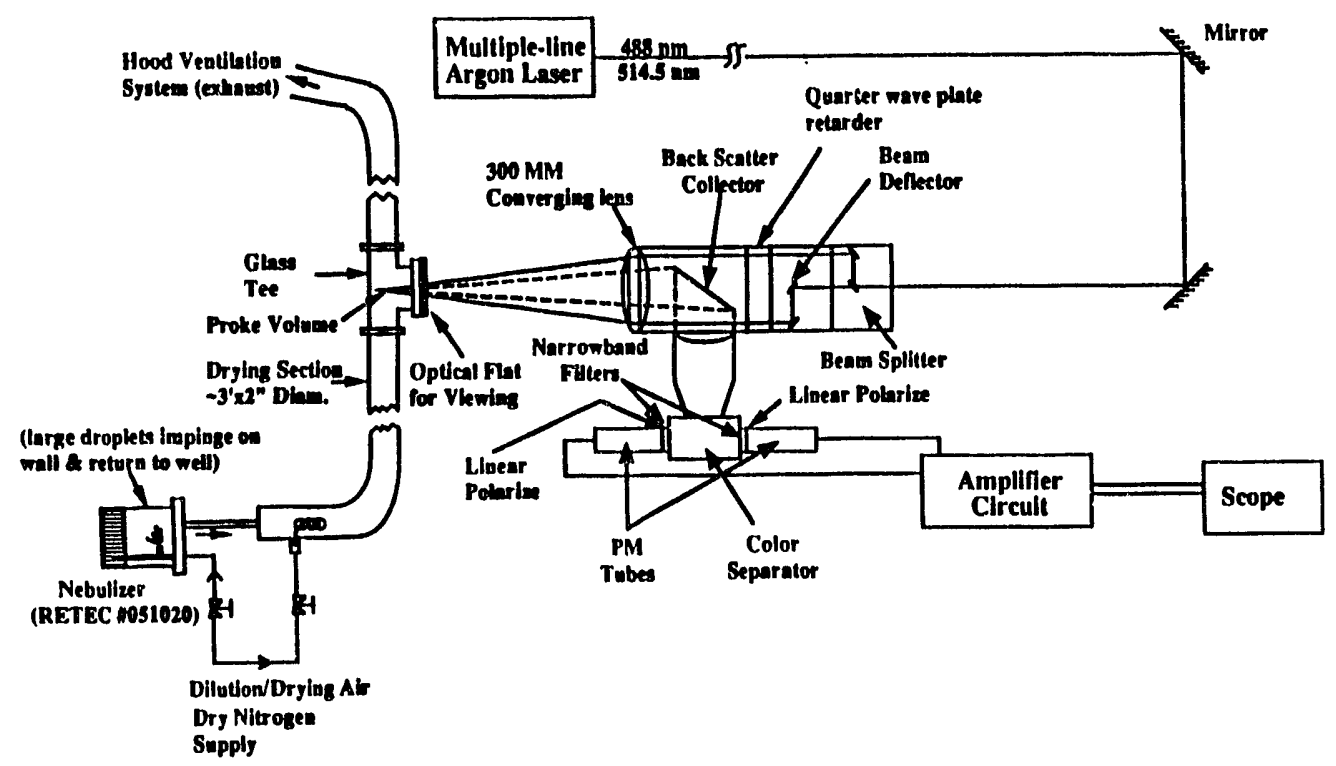

Fig. 5 Laboratory setup for observing visibility patterns of latex particles. (Schematic)

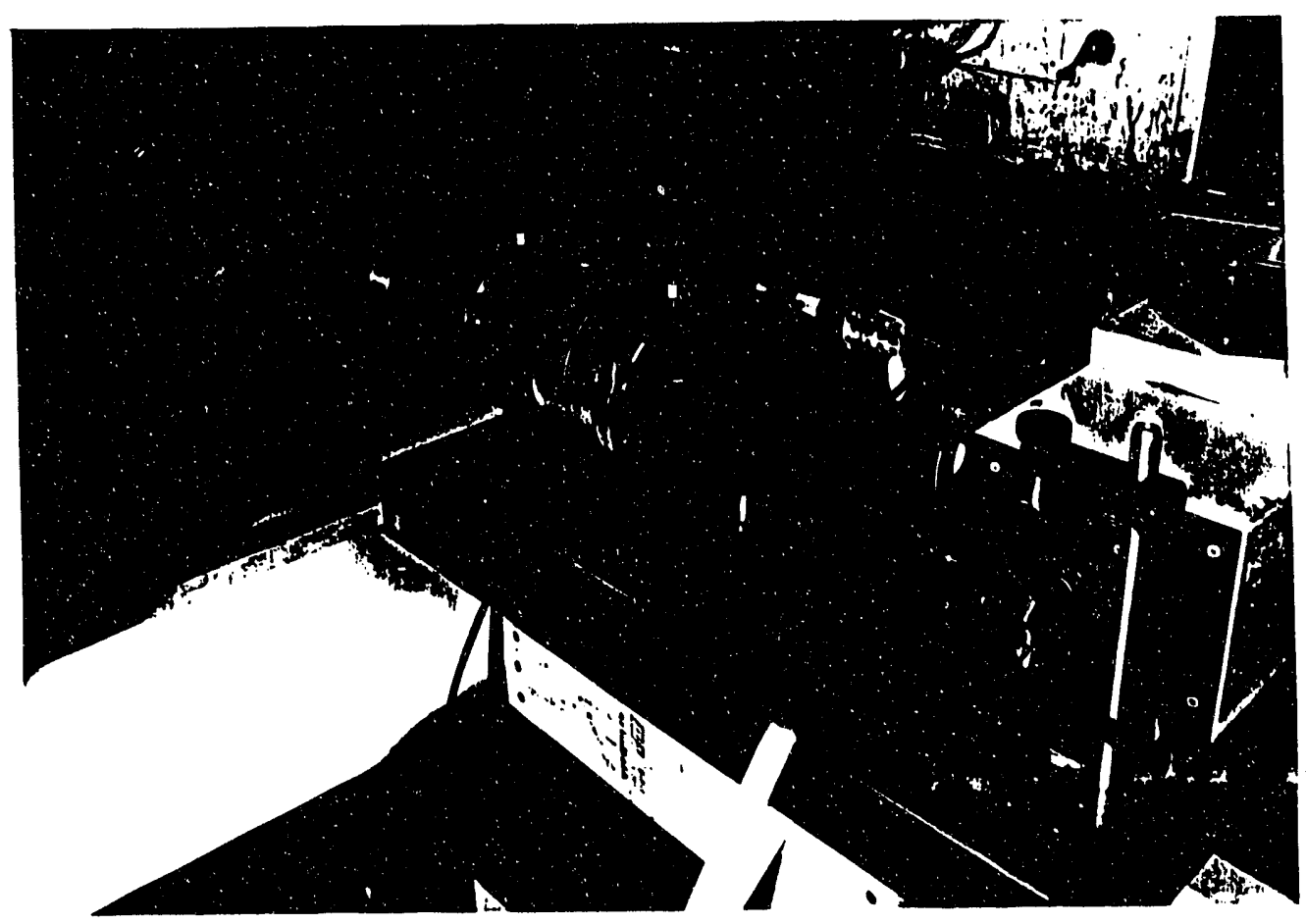

Fig. 6 Laboratory Setup for observing visibility patterns of latex particles. (Physical 


\section{EQUIPMENT SETUP AT GORGAS STEAM FACILITY}

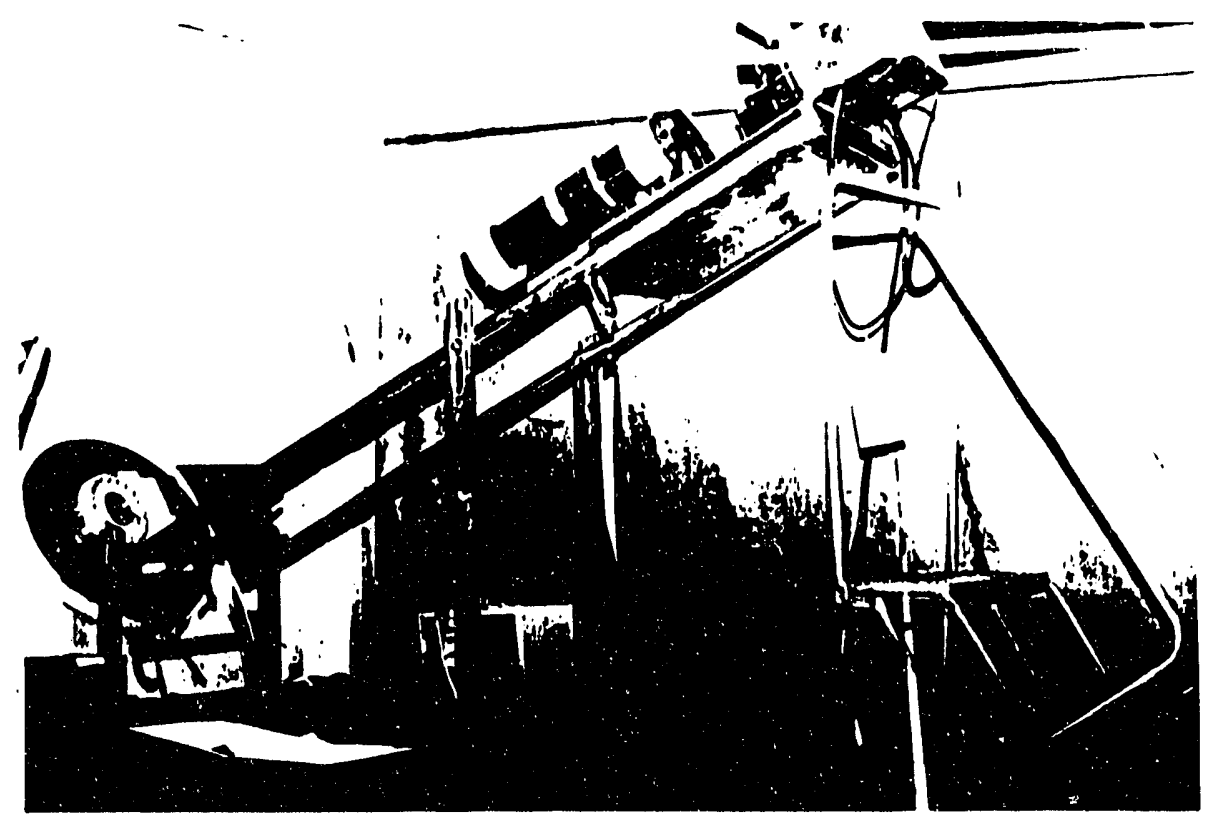

Fig. 11 Setup for observing visibility patterns of water droplets in the low pressure turbine. (Physical layout)

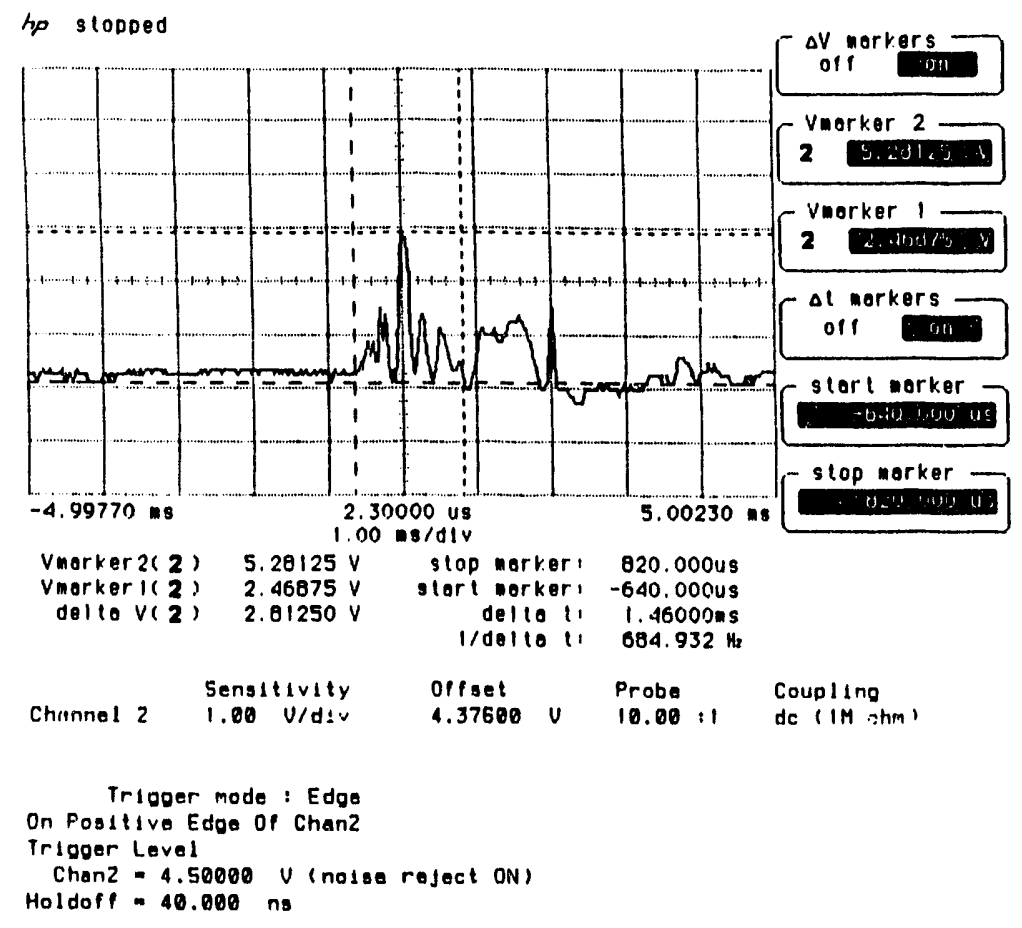

Fig. 12 Typical visibility pattern for a single water droplet in the LP turbine. 

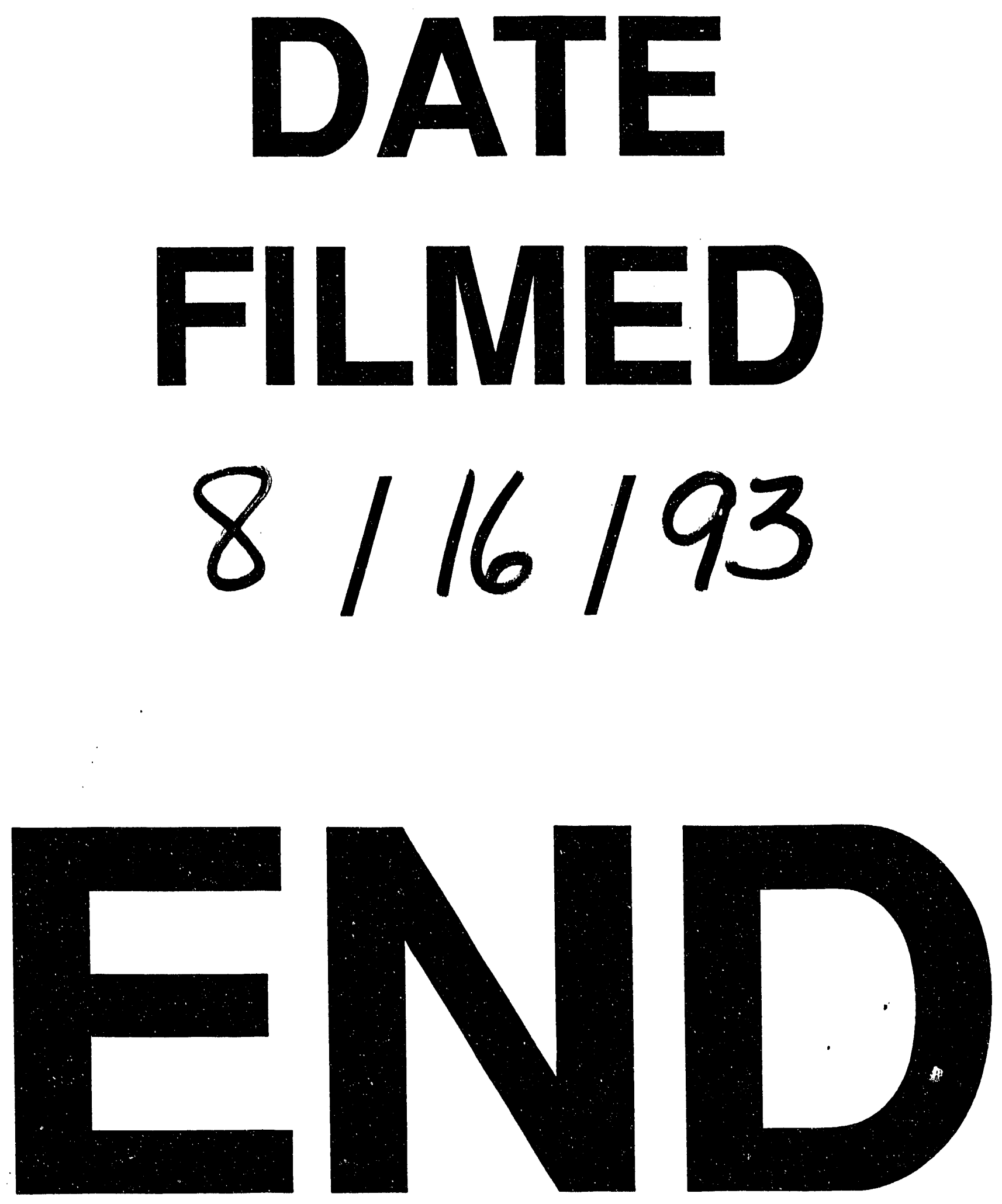
